\title{
Preface
}

Neonatology

\section{Sharing Progress in Neonatal (SPIN) Brain, Gut, Heart, and Lung}

\author{
Incorporating the 32nd International Workshop on Surfactant \\ Replacement, Dublin, May 26-27, 2017
}

The second Sharing Progress in Neonatology (SPIN) meeting incorporating the 32nd International Workshop on Surfactant Replacement took place in Dublin from May 26 to 27, 2017. Ireland is home to 2 of the authors (Henry Halliday and David Sweet) of the European guidelines on the management of respiratory distress syndrome [1], and so Dublin was a fitting venue for this meeting. Dublin is Ireland's largest city and very cosmopolitan with a rapidly developing global services hub. Ireland is the home of many literary scholars, such as Jonathan Swift, George Bernard Shaw, Oscar Wilde, James Joyce, Samuel Beckett, and Seamus Heaney, and Dublin, its vibrant and historic capital city, is steeped in culture.

The meeting was opened by Dominique Haumont from Brussels giving the 9th Bengt Robertson Memorial Lecture entitled: "eNewborn: the IT revolution and challenges for neonatal networks." The rapid improvements in neonatal outcomes and survival over the past few decades have been fuelled by the establishment and development of networks for benchmarking, such as the Vermont Oxford Network (VON) and the National Institutes of Child Health and Human Development Neonatal Research Network (NICHD-NRN), as well as corporate health care providers' networks, and regional and national networks [2]. Professor Haumont and her collaborators have developed an international network for evaluating the outcomes of very low birth weight, very preterm neonates (iNeo), which is a population-based group collating data from national neonatal networks including those of Australia, Canada, the UK, Israel, Japan, Sweden, Switzerland, and New Zealand [3]. The iNeo collaboration allows continuous quality improvement and is also a platform for future multicentre trials. She also discussed the new initiative of the International Neonatal Consortium, which aims to standardise and harmonise neonatal data to accelerate clinical research requiring big data technology [4].

The second invited speaker was Geraldine Boylan from Cork, who spoke about the importance of neonatal seizures. Professor Boylan has studied the effects of seizure burden on neurodevelopmental outcome. A high seizure burden was only associated with abnormal outcome in combination with moderate-to-severe injury on MRI [5]. In addition, a severely abnormal EEG background activity at $36-48 \mathrm{~h}$ after birth was associated with severe injury on MRI and an abnormal neurodevelopmental outcome. Studies by Professor Boylan and her colleagues have shown that even mild neonatal encephalopathy recognised by clinical signs and EEG analysis can be associated with adverse neurodevelopmental outcomes at 5 years [6]. However, recognition of neonatal seizures is challenging and at present requires specialist electrophysiology analysis of the EEG [7]. She is developing new technologies to quantify the seizure burden for clinicians at

\section{KARGER}

(C) 2017 S. Karger AG, Basel 
the bedside. These should also facilitate EEG interpretation and incorporation in rapid management decisions once validated.

David Warburton from Los Angeles gave an overview of lung development. He described the development of the lung with branching of the proximal airway and stereotypic branching of the proximal airway ends relatively early in utero at the bronchoalveolar duct junctions. He also described the development of alveoli in the immature lung and the long-term consequences on pulmonary function for survivors of preterm birth. Professor Warburton has demonstrated that tracheal occlusion blocks the outflow of secretions, producing a higher number of branching locations and increasing lung volume, as noted in studies of babies with congenital diaphragmatic hernia [8]. Other mechanical factors also influence lung development by interfering with fetal breathing movements or lung peristalsis to impair lung development [9].

In his talk entitled "What should we do about blood pressure in preterm infants?" Eugene Dempsey described the challenge regarding the interpretation of blood pressure values in the absence of a clear definition of normative values for preterm infants. The use of near infrared spectroscopy to understand systemic perfusion has been well studied by the multicentre Safe Boost study and holds promise once incorporated into routine management with other clinical indices of hypoperfusion [10]. Antenatal steroids and delayed cord clamping have decreased the incidence of hypotension, making it a more difficult condition to study. Professor Dempsey and his colleagues have described the policy of permissive hypotension in the management of hypotension as controversial, and long-term outcomes have not been studied for volume expansion or inotropes, such as dopamine, dobutamine, and epinephrine. The management of hypotension in preterm infants is the subject of a randomised controlled multicentre trial (HIP Trial) [11]. Professor Dempsey highlighted the challenges of recruitment in this population of critically ill preterm infants [12].

Boris Kramer from Maastricht updated the conference on "Surfactant for respiratory distress syndrome: new ideas on a familiar drug with innovative applications." Although surfactant is well studied in neonates, new research on the latest forms of surfactant, doses, and methods of administration is ongoing. Recent techniques, such as less invasive surfactant administration, using a catheter placed via Magills forceps instead of intubation have shown decreased morbidities, although not a consistent reduction in bronchopulmonary dysplasia (BPD) [13]. Minimally invasive surfactant therapy makes use of a rig-

Preface id adult vascular catheter without Magills forceps and is the subject of the OPTIMIST trial, which is currently recruiting. However, the issue of sedation during these procedures remains contentious and requires further randomised trials to define the optimal medication [14]. Although administration of surfactant via a laryngeal mask appears promising, it is as yet not widely studied. Nebulised surfactant appears safe but there are issues regarding adequate particle deposition and a phase II trial is ongoing. Future directions, including the administration of other medications with surfactant, were also discussed by Professor Kramer.

Henry Halliday from Belfast gave an update on postnatal steroid use for BPD. He noted that although antenatal steroids have significantly contributed to improved mortality and outcomes for preterm infants [15], controversies remain regarding timing, dose, and the delivery method for postnatal steroids [16]. Postnatal systemic steroid administration has been associated with an adverse neurodevelopmental outcome, especially if used in the first week of life [17]. In an effort to reduce morbidity, postnatal steroids have been administered by inhalation and the NEUROSIS trial showed a decrease in BPD and death [18]. However, long-term neurodevelopmental outcomes are yet to be reported and are needed before early inhaled steroids can be recommended for general use. Early inhaled budesonide combined with surfactant has shown benefits in decreasing BPD without a negative impact on neurodevelopmental outcome [19]. Professor Halliday concluded that whilst postnatal steroids may have a role in facilitating endotracheal intubation in ventilator-dependent preterm infants after the first week of life, further outcome data are required for definitive guidelines on the use of either systemic or inhaled steroids in the first week of life to prevent BPD.

Simon Eaton from London presented an overview of "Current research on the epidemiology, pathogenesis and management of necrotising enterocolitis." He highlighted the uncertainty surrounding pathogenesis and the lack of definitive diagnostic markers [20]. However, clinical machine-learning models allowing dynamic risk stratification have been successful. Specific gut biomarkers, such as I-FABP, have been less useful than markers of systemic inflammation, such as the non-specific cytokine IL-8. Predictive modelling using novel biomarkers (proteomics and metabolomics) and clinical data may be useful for an early diagnosis and the response to treatment. Dr. Eaton also explored the role of probiotics, feeding regimens, lactoferrin, stem cells, and specific TLR4 receptor antagonists as therapeutic agents [21].

Neonatology 2017;111:384-387 DOI: $10.1159 / 000464316$ 
Saving 1 million lives per year in low- and middle-income countries was the topic of Wally Carlo's presentation. He described the massive improvement in neonatal mortality by initiating multilayered education programmes using train-the-trainer methods aligned to the neonatal resuscitation program and Helping Babies Breathe courses. It is estimated that resuscitation and immediate care packages could save over a million lives per year [22] in low- and middle-income countries, and Professor Carlo from Birmingham, Alabama, shared his experiences of these programmes during his talk to an enrapt audience. Collaborative research between developing and developed countries is extremely important and has major clinical and economic consequences.

Nicola Robertson from University College London, UK, spoke about the future of neonatal neuroprotection. Potential newer adjunctive therapies may target excitatory neurotransmitter production, or decreasing inflammation and free radical production and neurogenesis [23]. Professor Robertson and her colleagues have developed MRI biomarkers of outcomes and, in combination with preclinical studies of neuroprotectants, have made major advances in this field. Her group has developed piglet models of neonatal encephalopathy and demonstrated improved outcome if melatonin is added as an adjunct to hypothermia [24]. Professor Robertson has also published on potential neuroprotectants, including remote ischaemia preconditioning, melatonin, erythropoietin, cannabinoids, and xenon [25], some of which hold promise in decreasing longterm disability following neonatal encephalopathy.

The SPIN update comprised highly relevant and excellent talks on vital subjects in neonatology. Jatinder Bhatia from Augusta, USA, discussed optimal methods of nourishing preterm infants. Samir Gupta from Middlesbrough, UK, described the modern management of pat- ent ductus arteriosus, which is still a somewhat controversial topic. Mark Turner from Liverpool, UK, gave an overview of neonatal drug development, including surfactant and beyond. Finally, Luca Ramenghi from Genoa, Italy, spoke about the role of insulin growth factor-1 in the retinopathy of prematurity. The meeting also included 15 short oral communications and 22 poster presentations. Some of the review papers from the meeting and the free oral communications are published in this issue of Neonatology. The debt owed to the late Professor Bengt Robertson, who initiated this series of workshops that have continued for more than 30 years, is again acknowledged. Bengt Robertson was a huge contributor to our knowledge and understanding of neonatal respiratory distress syndrome and the role of surfactant [26]. We are sure he would appreciate the broader remit of the workshops which now encompass all areas of progress in neonatology, including neurology, gastroenterology, cardiology, and ophthalmology. The third SPIN meeting will be held in 2018 in Lübeck, Germany.

$$
\begin{aligned}
& \text { Eleanor J. Molloy, Dublin } \\
& \text { Tore Curstedt, Stockholm } \\
& \text { Henry L. Halliday, Belfast } \\
& \text { Mikko Hallman, Oulu } \\
& \text { Ola D. Saugstad, Oslo } \\
& \text { Christian P. Speer, Würzburg }
\end{aligned}
$$

\section{Disclosure Statement}

The scientific programme was arranged by the Scientific Committee without the interference of the sponsors. Members of the Scientific Committee are or have been consultants to Chiesi Farmaceutici, Parma, Italy. The content of the meeting and the workshop reflects the scientific opinions of the individual presenters and not the sponsor or its partners.

\section{References}

1 Sweet DG, Carnielli V, Greisen G, Hallman M, Ozek E, Plavka R, Saugstad OD, Simeoni U, Speer CP, Vento M, Visser GH, Halliday HL: European consensus guidelines on the management of respiratory distress syndrome - 2016 update. Neonatology 2017;111: $107-125$.

2 Shah V, Warre R, Lee SK: Quality improvement initiatives in neonatal intensive care unit networks: achievements and challenges. Acad Pediatr 2013;13(6 suppl):S75-S83.

- 3 Shah PS, Lee SK, Lui K, Sjörs G, Mori R, Reichman B, Håkansson S, Feliciano LS, et al: The International Network for Evaluating
Outcomes of very low birth weight, very preterm neonates (iNeo): a protocol for collaborative comparisons of international health services for quality improvement in neonatal care. BMC Pediatr 2014;4:110.

-4 Turner MA, Davis JM, McCune S, Bax R, Portman RJ, Hudson LD: The International Neonatal Consortium: collaborating to advance regulatory science for neonates. Pediatr Res 2016;80:462-464.

5 Weeke LC, Boylan GB, Pressler RM, Hallberg B, Blennow M, Toet MC, Groenendaal F, de Vries LS: Role of EEG background activity, seizure burden and MRI in predicting neuro- developmental outcome in full-term infants with hypoxic-ischaemic encephalopathy in the era of therapeutic hypothermia. Eur J Paediatr Neurol 2016;20:855-864.

6 Murray DM, O'Connor CM, Ryan CA, Korotchikova I, Boylan GB: Early EEG grade and outcome at 5 years after mild neonatal hypoxic ischemic encephalopathy. Pediatrics 2016; 138:e20160659.

-7 Stevenson NJ, Clancy RR, Vanhatalo S, Rosén I, Rennie JM, Boylan GB: Interobserver agreement for neonatal seizure detection using multichannel EEG. Ann Clin Transl Neurol 2015;2:1002-1011.
386

Neonatology 2017;111:384-387 DOI: $10.1159 / 000464316$
Molloy/Curstedt/Halliday/Hallman/

Saugstad/Speer 
8 George UZ, Bokka KK, Warburton D, Lubkin SR: Quantifying stretch and secretion in the embryonic lung: implications for morphogenesis. Mech Dev 2015;138:356-363.

-9 Miller AA, Hooper SB, Harding R: Role of fetal breathing movements in control of fetal lung distension. J Appl Physiol 1993; 75:27112717.

10 Pellicer A, Greisen G, Benders M, Claris O, Dempsey E, Fumagally M, Gluud C, et al: The SafeBoosC phase II randomised clinical trial: a treatment guideline for targeted near-infrared-derived cerebral tissue oxygenation versus standard treatment in extremely preterm infants. Neonatology 2013;104:171-178.

11 Dempsey EM, Barrington KJ, Marlow N, O'Donnell CP, Miletin J, Naulaers G, Cheung P-Y, Corcoran D, Pons G, Stranak Z, van Laere D: Management of Hypotension in Preterm Infants (The HIP Trial): a randomised controlled trial of hypotension management in extremely low gestational age newborns. Neonatology 2014;105:275-281.

-12 Dempsey EM, Al Hazzani F, Barrington KJ: Permissive hypotension in the extremely low birthweight infant with signs of good perfusion. Arch Dis Child Fetal Neonatal Ed 2009; 94:F241-F244.

13 Klebermass-Schrehof K, Wald M, Schwindt J, Grill A, Prusa AR, Haiden N, Hayde M, Waldhoer T, Fuiko R, Berger A: Less invasive sur- factant administration in extremely preterm infants: impact on mortality and morbidity. Neonatology 2013;103:252-258.

14 Dekker J, Lopriore E, Rijken M, Rijntjes-Jacobs E, Smits-Wintjens V, Te Pas A: Sedation during minimal invasive surfactant therapy in preterm infants. Neonatology 2016;109:308313.

15 Dalziel SR, Lim VK, Lambert A, McCarthy D, Parag V, Rodgers A, Harding JE: Antenatal exposure to betamethasone: psychological functioning and health related quality of life 31 years after inclusion in a randomised controlled trial. BMJ 2005;331:665-668.

16 Halliday HL: Postnatal steroids: the way forward. Arch Dis Child Fetal Neonatal Ed 2011; 96:F158-F159.

17 Doyle LW, Halliday HL, Ehrenkranz RA, Davis PG, Sinclair JC: An update on the impact of postnatal systemic corticosteroids on mortality and cerebral palsy in preterm infants: effect modification by risk of bronchopulmonary dysplasia. J Pediatr 2014;165:12581260.

18 Bassler D, Plavka R, Shinwell ES, Hallman M, Jarreau PH, Carnielli V, et al; NEUROSIS Trial Group: Early inhaled budesonide for the prevention of bronchopulmonary dysplasia. N Engl J Med 2015;373:1497-1506.

19 Yeh TF, Chen CM, Wu SY, Husan Z, Li TC, Hsieh WS, Tsai $\mathrm{CH}$, Lin HC: Intratracheal administration of budesonide/surfactant to prevent bronchopulmonary dysplasia. Am J Respir Crit Care Med 2016;193:86-95.

20 Neu J: Necrotizing enterocolitis: the mystery goes on. Neonatology 2014;106:289-295.

21 Abdulkadir B, Nelson A, Skeath T, Marrs EC, Perry JD, Cummings SP, Embleton ND, Berrington JE, Stewart CJ: Routine use of probiotics in preterm infants: longitudinal impact on the microbiome and metabolome. Neonatology 2016;109:239-247.

22 Little G, Niermeyer S, Singhal N, Lawn J, Keenan W: Neonatal resuscitation: a global challenge. Pediatrics 2010;126:e1259-e1260.

23 van Bel F, Groenendaal F: Long-term pharmacologic neuroprotection after birth asphyxia: where do we stand? Neonatology 2008;94:203-210.

24 Robertson NJ, Faulkner S, Fleiss B, Bainbridge A, Andorka C, Price D, Powell E, et al: Melatonin augments hypothermic neuroprotection in a perinatal asphyxia model. Brain 2013;136:90-105.

25 Hassell KJ, Ezzati M, Alonso-Alconada D, Hausenloy DJ, Robertson NJ: New horizons for newborn brain protection: enhancing endogenous neuroprotection. Arch Dis Child Fetal Neonatal Ed 2015;100:F541-F552.

-26 Halliday HL, Speer CP: Bengt Robertson (1935-2008): a pioneer and leader in surfactant research. Neonatology 2009;95:VI-VII. 